\title{
Registration of two rice mapping populations using weedy rice ecotypes as a novel germplasm resource
}

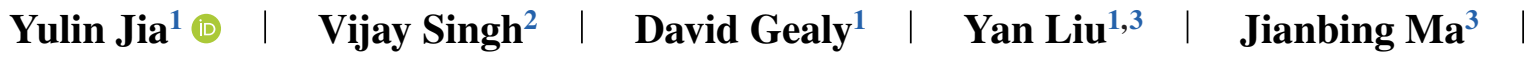

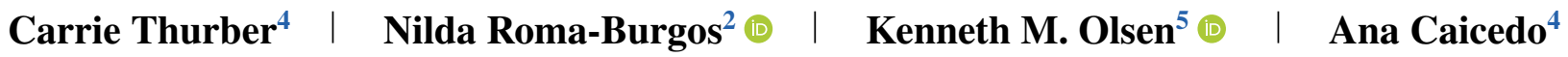

${ }^{1}$ USDA-ARS Dale Bumpers National Rice Research Center, 2890 Hwy 130E, Stuttgart, AR 72160, USA

${ }^{2}$ Dep. of Crop, Soil, and Environmental Sciences, Univ. of Arkansas, Fayetteville, AR 72701, USA

${ }^{3}$ Rice Research and Extension Center, Univ. of Arkansas, Stuttgart, AR 72160, USA

${ }^{4}$ Dep. of Biology, Univ. of Massachusetts, Amherst, MA 01003, USA

${ }^{5}$ Dep. of Biology, Washington Univ., St. Louis, MO 63130, USA

\section{Correspondence}

Yulin Jia, USDA-ARS Dale Bumpers

National Rice Research Center, 2890 Hwy 130E, Stuttgart, AR 72160, USA.

Email:Yulin.Jia@usda.gov

Assigned to Associate Editor Adam Famoso.

Funding information

National Science Foundation, Grant/Award Numbers: NSF awards IOS-1032023,

PGR1947609

Registration by CSSA.

\begin{abstract}
Two mapping populations were developed from crosses of the Asian indica rice (Oryza sativa L.) cultivar 'Dee Geo Woo Gen’ (DGWG; PI 699210 Parent, PI 699212 Parent) and two weedy rice ecotypes, an early-flowering straw hull (SH) biotype AR-2000-1135-01 (PI 699209 Parent) collected in Arkansas and a late-flowering black hull (BHA) biotype MS-1996-9 (PI 699211 Parent) collected in Mississippi. The weed and crop-based rice recombinant inbred line (RIL) mapping populations have been used to identify genomic regions associated with weedy traits as well as resistance to sheath blight and rice blast diseases. The mapping population consists of 185 (DGWG/SH; Reg. no. MP-9, NSL 541035 MAP) and 234 (BHA/DGWG; Reg. no. MP-10, NSL 541036 MAP) $F_{8}$ RILs, of which 175 (DGWG/SH) and 224 (BHA/DGWG) were used to construct two linkage maps using single nucleotide polymorphic markers to identify weedy traits, sheath blight, and blast resistance loci. These mapping populations and related datasets represent a valuable resource for basic rice evolutionary genomic research and applied marker-assisted breeding efforts in disease resistance.
\end{abstract}

\section{1 | INTRODUCTION}

Weedy rice, composed of plants in the genus Oryza, is a major agricultural pest worldwide. Weedy rice is a highly troublesome, widespread, and persistent weed of rice; it is often the same species as the crop (Oryza sativa L.) but can also have origins in wild Oryza species. Weedy rice is often taller than cultivated rice, resulting in crop lodging; has strong seed dor-

Abbreviations: BHA, MS-1996-9; DAH, days after harvest; DGWG, 'Dee Geo Woo Gen'; RIL, recombinant inbred line; SH, AR-2000-1135-01; SNP, single nucleotide polymorphism; SSD, single seed descent. mancy and grain shattering, resulting in persistence in the soil; and has red bran grains that reduce grain quality; all these factors reduce crop value. For more than a century weedy rice has infested rice fields throughout the Mississippi River Valley and Gulf Coast of the southern United States in the states of Arkansas, Louisiana, Mississippi, Texas, and Missouri, where $\sim 80 \%$ of the country's rice is grown (Delouche et al., 2007; Jia \& Gealy, 2018; Ziska et al., 2015). Recently, weedy rice has been identified as a resurging problem in a few isolated areas in California after it had been nearly eliminated by the mid-1950s using water seeding cultural management practices and certified seed programs (Delouche et al., 2007; Jia 
\& Gealy, 2018; Kanapeckas et al., 2016; Karn et al., 2020). In Arkansas alone, where nearly half of all U.S. rice is produced, weedy rice consistently ranks among the three most important weeds in rice cultivation, after barnyardgrass and pigweed (Gealy et al., 2019; Norsworthy et al., 2007; Norsworthy et al., 2013; Smith, 1988). Yield loss due to weedy rice varies according to plant type, density, duration of competition, and rice variety. One weedy rice $\mathrm{m}^{-2}$ has been reported to reduce the yield of a modern rice cultivars 'CL161' and 'Cocodrie' by $10 \%$ in Arkansas (Ottis et al., 2005). Total annual economic losses due to this weed have been estimated at US\$93 million in Arkansas (Burgos et al., 2008).

The accumulated data show that weedy rice most commonly evolves from domesticated rice, either directly via dedomestication or with varying degrees of hybridization with wild rice species (Li \& Olsen, 2020; Qiu et al., 2020). The two major groups of weedy rice genotypes infesting modern day rice fields of the southern United States are straw hull (with no awns) and black hull (with long awns) for the general coloration of the seed hulls (Shivrain et al., 2010b). These genotypes were probably introduced into the United States independently from different regions of Asia and at different times in the distant past (Londo \& Schaal, 2007; Reagon et al., 2010). It is thought that weedy rice likely first arrived in what is now the United States in 1698 or earlier as contaminants in rice seed when rice was first being introduced into the colony of South Carolina for cultivation. It later became well documented that weedy rice was a serious problem in rice in North Carolina and South Carolina by the mid-1800s, that the problem had expanded into all of the newer rice-producing states (Georgia, Louisiana, and Arkansas) by 1900, and that by the early 1920 s was a serious problem in all of the major presentday rice-producing states (Arkansas, Louisiana, Mississippi, Missouri, Texas, and California) (Delouche et al., 2007).

Straw hull genotypes are genetically closely related to cultivated indica rice, whereas black hull genotypes are more closely related to cultivated aus rice, and both apparently evolved primarily through de-domestication processes from cultivated rice in these subpopulations, with the black hull type arising several thousand years earlier than the straw hull type (Li et al., 2017; Londo \& Schaal, 2007; Reagon et al., 2010; Shivrain et al., 2010a). Since their initial introduction into southern U.S. rice fields in the last several hundred years, these two weedy rice genotype groupings have evolved into more morphologically diverse populations via low-level hybridization between themselves or with the crop, but they are still largely identifiable as distinct straw hull and black hull groups (Delouche et al., 2007; Gealy et al., 2012; Londo \& Schaal, 2007; Reagon et al., 2010; Shivrain et al., 2010b). The weedy rice types recently identified in California have genetic backgrounds quite different from, and evolutionarily more recent than, those in the southern United States (De Leon et al., 2019; Kanapeckas et al., 2016).

\section{Core Ideas}

- Weedy rice competing with cultivated rice is a major pest.

- Weedy rice can benefit germplasm improvement and weed control.

- Two contrasting crop-weed populations are ideal for basic evolutionary genomic research.

- Abundant genotypic and phenotypic data are ready for the users to analyze.

- SNP-linked traits are useful for marker assisted breeding.

To understand the molecular basis of the evolutionary dynamics of the important genes underlying weedy traits, two recombinant inbred line (RIL) mapping populations were developed using a single seed descent (SSD) breeding method. Two weedy rice ecotypes, an early-flowering straw hull type AR-2000-1135-01 (PI 699209 Parent) from Arkansas (SH) and a late-flowering black hull type MS-19969 (PI 699211 Parent) from Mississippi (BHA), were crossed with the Asian indica rice cultivar 'Dee Geo Woo Gen' (DGWF), a putative evolutionarily close relative (Liu et al., 2015a). DGWG is the carrier for semidwarf 1 gene $S D 1$, and this rice cultivar played an important role in the development of Green Revolution cultivars (Liu et al., 2015a). The populations derived from the cross of DGWG (PI 699210 Parent) and SH (DGWG/SH; Reg. no. MP-9, NSL 541035 MAP) and the cross of BHA and DGWG (PI 699212 Parent) (BHA/DGWG; Reg. no. MP-10, NSL 541036 MAP) consist of 185 and 234 RILs, respectively.

The populations were evaluated for nine agronomic traits that include seedling growth rate (i.e., days to emergence), phenology (i.e., days to heading), plant height, canopy structure (tiller angle), number of tillers, and awnedness. Weedy rice generally grows faster and taller and produces more tillers that occupy more space because of wider culm angles; these traits increase the competitive ability of weedy rice. Some physiological traits were also evaluated, including seed dormancy and reactions to rice blast (caused by Magnaporthe oryzae) and sheath blight (caused by Rhizoctonia solani) fungi in replicated field plots and greenhouse experiments in the summers of 2012-2018. All RILs, including parents, were sequenced using the genotyping $\times$ sequencing method. A total of 6,016 single nucleotide polymorphism (SNP) markers between DGWG and SH and 13,730 between BHA and DGWG were used to construct densely covered marker linkage maps. Important genomic regions associated with weedy traits, including resistance to rice blast disease, were established by associating phenotypic data and SNP genotypical 
data. Thus far, these two mapping populations have been used to understand evolutionary mechanisms of weedy rice (Qi et al., 2015) and to identify rice blast disease resistance genes (Liu et al., 2015a, 2015b), genes controlling root system architecture in weedy rice (Wedger et al., 2019), and sheath blight disease resistance genes (Goad et al., 2020) as well as the genetic bases of U.S. weedy rice evolution based on weedy traits, including shattering (Qi et al., 2015; Thurber et al., 2013).

\section{2 | METHODS}

\section{1 | Parents}

An early-flowering straw hull genotype, AR-2000-1135-01 (PI 653435), from Arkansas (SH) and a late-flowering black hull genotype, MS-1996-9 (PI 653419), from Mississippi (BHA) were used as weedy rice parents for the populations developed in this study (Jia \& Gealy, 2018). Mature plant heights and times to $50 \%$ heading were $149 \mathrm{~cm}$ and $71 \mathrm{~d}$, respectively, for the straw hull genotype and $169 \mathrm{~cm}$ and $85 \mathrm{~d}$, respectively, for the black hull genotype. Both $\mathrm{SH}$ and BHA were crossed with DGWG to produce two comparative mapping populations.

\section{2 | Population development}

The indica cultivar DGWG was the female parent in the DGWG $\times$ SH cross, whereas the weedy rice BHA was the female parent in the BHA $\times$ DGWG cross. The crosses of weed and crop accessions were made in 2009 at the Department of Biology, University of Massachusetts, Amherst, MA. Bulked seeds from $\mathrm{F}_{1}$ plants verified with a SNP marker were used to produce the $F_{2}$ population in 2010. Subsequently, the population was advanced using the SSD breeding method in greenhouses at the Dale Bumpers National Rice Research Center near Stuttgart, AR. The population was advanced two generations in each year from 2011 to 2012 using SSD. A single seed derived from each $\mathrm{F}_{7}$ individual harvested in a greenhouse in April 2013 was grown in the field in 2013, and single plants were bulk harvested for germplasm release at the $\mathrm{F}_{8}$ generation. Information on the time of measurement and replication of both mapping populations is provided in Supplemental Figure S1.

\section{3 | Rice blast disease evaluation}

Blast disease reactions of the mapping population were performed as previously described (RoyChowdhury et al., 2012). Specifically, four to seven rice seedlings at 3-4 leaf stages were inoculated with freshly prepared blast spores. After inoculation, plants were sealed in plastic bags overnight. Then inoculated plants were removed from the bag and moved to a blast developing room in a greenhouse at $80 \%$ relative humidity and $26.7^{\circ} \mathrm{C}$ for an additional $6 \mathrm{~d}$ prior to scoring disease reactions. A single score was given to each RIL for the reaction of the second youngest leaf of four to seven seedlings. The disease reaction was evaluated based on a $0-5$ scale, where 0-2 represents different levels of resistance and 3-5 represents different levels of susceptibility ( 0 , no visible disease lesion; 1 , one to five brown spots without any fungal mycelia; 2 , more than five brown spots without any fungal mycelia; 3 , at least one lesion with visible fungal mycelia; 4 , more than five lesions with fungal mycelia; and 5, more than 10 lesions with fungal mycelia).

\section{4 | Sheath blight disease reactions}

The field isolate Rhizoctonia solani (AG1-IA) RR0134 (Wamishe et al., 2007), grown on a mixture of sterilized corn chops and rye, was used for field inoculation and evaluation as described (Goad et al., 2020; Liu et al., 2013). Specifically, each line of the mapping populations was planted in three replicates using a complete block design. The susceptible cultivar 'Lemont' was used as a border. Rice plants with a main tiller one-half inch in diameter (approximately at the late tiller stage) in a three-row plot with the center row were inoculated with a mixture of air-dried mycelia and sclerotia of $R$. solani. Approximately 3 wk after inoculation, the plants in the middle row were scored from the base of the plant to the panicle for disease lesions. For each $10 \%$ of the plant with lesions, the score was increased by an increment of $1(10 \%=1,20 \%=2 \ldots 90 \%=9)$, with a lesion at the panicle being scored as 9 . The sheath blight evaluation under field conditions was conducted in 2015 and 2016.

\section{5 | Agronomic traits}

Phenotypic data for seven traits were collected from 2012 to 2016, either in field plots or in the greenhouse, at the Dale Bumpers National Rice Research Center (Stuttgart, AR). The following traits were assessed: seedling emergence, heading date, plant height, tiller number, leaf relative chlorophyll content, plant type, and awns. Seedling emergence date was counted as the number of days from sowing to $50 \%$ seedling emergence. Heading date was calculated as the number of days from sowing to $\geq 50 \%$ of plants within a RIL having one or more tillers with an inflorescence at anthesis. Plant height was measured from the tip of panicle to the ground of a mature plant at harvest. The number of productive tillers (with filled grain) was counted with the average of four plants per 


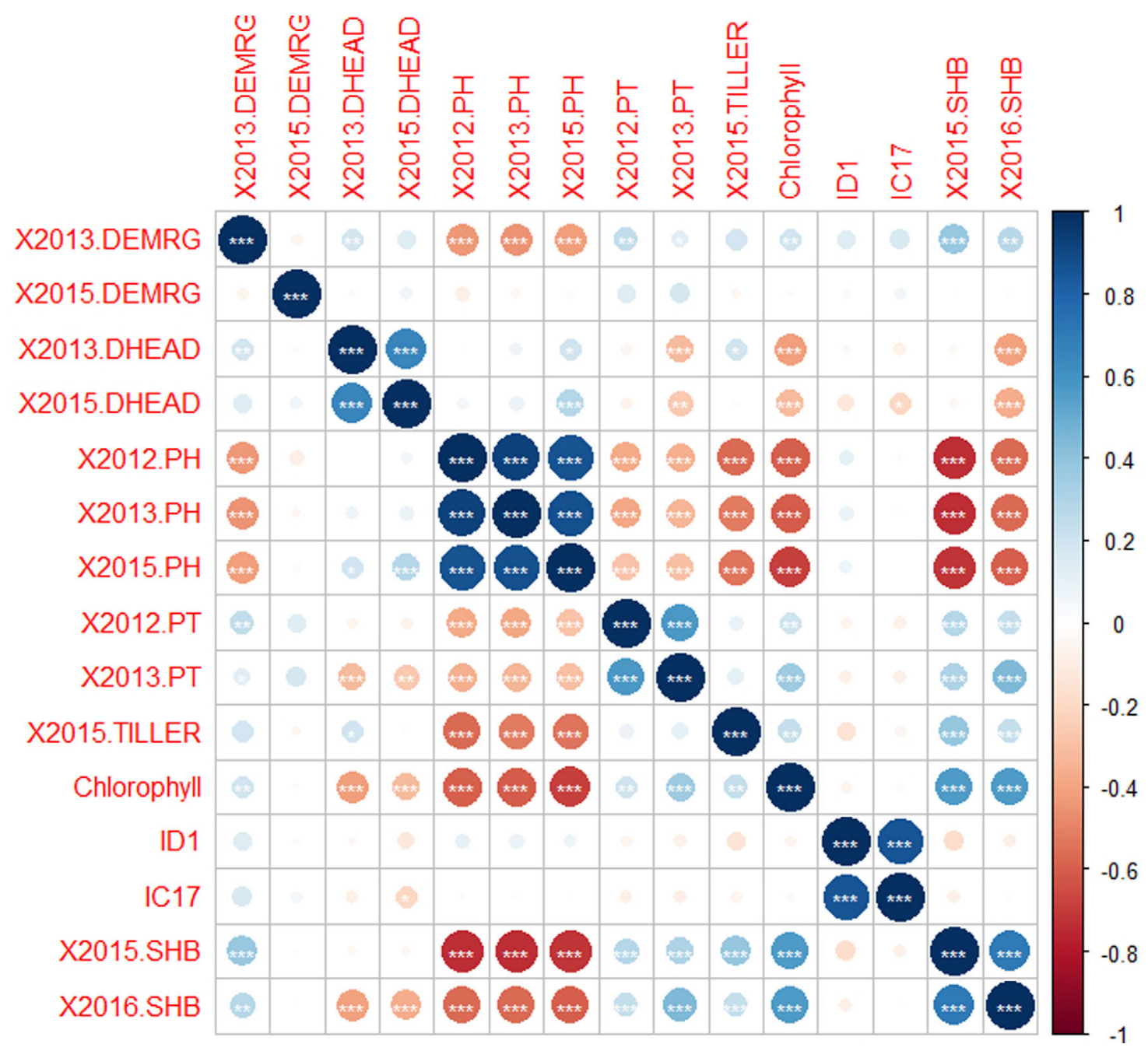

F I G U R E 1 Pearson's correlation matrix for all traits in the Table 1. The shaded scale refers to the strength of correlation. Significance levels (*95\%,**99\%,***99.9\%) are indicated. DEMRG, days to emergence; DHEAD, days to heading; ID1, IC17, blast races; PH, plant height; PT, plant type; SHB, sheath blight reaction; TILLER, number of tillers. Years are indicated after X

pot for SH and three plants per pot for BHA mapping populations at maturity in a greenhouse in 2015. The leaf relative chlorophyll content (unitless) was determined in 2013 (Zhu et al., 2012). Specifically, at $6 \mathrm{~d}$ after heading, flag leaves per line per replication were measured, and data from three replications per RIL were collected in the field in 2013 using a LEAF chlorophyll meter that evaluates transmittance of light wavelengths associated with chlorophyll absorbance. Unitless rice descriptors established by the International Rice Research Institute were used to describe the plant type (tiller angle scale of $1=$ erect, $3=$ intermediate, $5=$ open, $7=$ spreading, or $9=$ procumbent) and to describe the awns on spikelets (on a scale of $0=$ absent, $1=$ short and partly awned, $5=$ short and fully awned, $7=$ long and partly awned, $9=$ long and fully awned). The data for awn were not collected from DGWG/SH mapping population because both parents and progeny were awnless.

A randomized complete block design with three replicate blocks was used for field studies. For each replication, several seeds per RIL were sown in a single hill plot using a drill planter, and five plants were kept for each RIL. Fields were flooded when the seedlings reached the 4- to 7-leaf stage. Plants were spaced $30 \mathrm{~cm}$ apart within and $61 \mathrm{~cm}$ between rows. Each replicate block had five hill plots per row for each $\mathrm{RIL}$, and all were contained within a bay measuring $\sim 40 \mathrm{~m}$ by $\sim 16 \mathrm{~m}$.

A total of 10 panicles were bulk harvested for each RIL of two populations, including 234 RILs derived from the cross of BHA $\times$ DGWG and 185 RILs derived from the cross of DGWG $\times$ SH between October and November in 2012 and 2013. 


\subsection{Dormancy}

The mapping populations were evaluated in the field in the summer of 2012, and the harvested $F_{7}$ seeds were tested for dormancy $150 \mathrm{~d}$ after harvest (DAH). Similarly, $\mathrm{F}_{8}$ seeds were harvested from RILs in the fall of 2013, and a dormancy test was conducted at $90 \mathrm{DAH}$. Samples were air-dried in paper bags for 5 mo at room temperature for $\mathrm{F}_{7}$ seeds (2012) and 3 mo for $F_{8}$ seeds (2013). Seeds of $F_{7}$ and $F_{8}$ RILs and parental materials (SH, BHA, DGWG) were tested in batches according to the respective harvest week of each plant. Twenty seeds from each RIL and field replication were placed in a Petri dish $(9 \mathrm{~cm}$ diameter), replicated three times, moistened with $6 \mathrm{ml}$ deionized water, and dark-incubated in a growth chamber at $30{ }^{\circ} \mathrm{C}$. The Petri dishes were placed in trays, and the trays were arranged in a randomized complete block design in the growth chamber. The trays were covered with a plastic sheet to prevent desiccation and were re-watered every $4 \mathrm{~d}$ until termination of the study on the 12th day. A germination count was conducted at 6 and $12 \mathrm{~d}$ after placing in the growth chamber. Seeds were considered germinated when the radicle protruded from the caryopsis. A subsample of 10 RILs was tested for viability using the tetrazolium test and compared with the seed-firmness test for dormancy (Singh et al., 2017). Both tests produced the same viability results; thus, firm, non-germinated seeds were counted as viable, dormant seeds. The objective of the study was to differentiate dormancy levels among the RILs within a generation, not to compare dormancy at different times after harvest. In 2012, we tested $F_{7}$ seeds at $150 \mathrm{DAH}$ to ensure that the dormancy phenotype was already set. With this seed storage duration, the dormancy among RILs did not differ, but the variation within RILs was high. It seemed like plants within RIL were still segregating. During the same period, dormancy experiments had been conducted on a large number of weedy rice populations from Arkansas, which showed that the dormancy phenotype is already optimally set at $90 \mathrm{DAH}$. Therefore, in 2013, we tested the dormancy of $\mathrm{F}_{8}$ seeds at $90 \mathrm{DAH}$ with the expectation of finding significant differences in dormancy among RILs. The differences in generation $\left(\mathrm{F}_{7}\right.$ and $\left.\mathrm{F}_{8}\right)$ and test timings were collectively considered as experiment run or repetition for analysis.

\section{$2.7 \quad$ Data analysis}

Data for sheath blight ratings and agronomic traits were analyzed using SAS Version 9.3, 2002-2010 (SAS Institute Inc.). The analysis was done using Proc GLM (SAS v.9.3). Other statistics, including ANOVA, were performed using Proc Univariate, Proc Freq. The correlation of phenotypic data was analyzed with Pearson's correlation matrix using the $\mathrm{R}$ environment correlplot package. The ANOVA was conducted using field replication as random effect, and Tukey's honestly significant difference $(\alpha=.05)$ was used to compare the dormancy means. For genotype group comparisons, contrast analysis (e.g., Gonzalez, 2019) was conducted to compare dormancy of RIL group and parent genotypes (SH, BHA, DGWG) and comparisons between parent genotypes (excluding RILs). Significance was evaluated based on $F$-test $(\alpha=.05)$ in JMP Pro (Version 15 , SAS Institute Inc.).

\section{3 | CHARACTERISTICS}

\section{1 | Population properties}

Means and ranges for days to heading, plant height, plant type, chlorophyll content, number of tillers, and rice blast and sheath blight reactions of the DGWG/SH and BHA/DGWG populations, as well as the parents, are summarized in Tables 1 and 2, respectively. Correlations among all traits are summarized in Figures 1 and 2. Plant height, plant type, and sheath blight reactions were well correlated among individuals in both mapping populations (Figures 1 and 2). Correlations between disease reaction to the blast races ID1 and IC17 in the SH population and among the races IB33, IC1, IC17, ID1, and IE1 in the BHA population suggest the presence of common blast resistance genes with overlapping resistance spectra exist in these two populations (Liu et al., 2015a). Transgressive segregation was observed among all traits except awns in the BHA/DGWG population (Supplemental Figure S2). Taken together, these findings suggest that both DGWD/SH and BHA/DGWG populations are an excellent resource for identifying novel genes for agronomic, physiologic, and disease-related traits.

\section{2 | Dormancy}

Approximately 41\% of the DGWG/SH RILs in 2012 matured and were harvested during the 42nd Julian week, whereas harvesting of most of the BHA/DGWG RILs (66\%) in 2013 was spread over the 42nd and 44th Julian weeks (Figure 3; Supplemental Tables S3-S6).

The viability of RILs, irrespective of population, varied from 75 to $100 \%$ in 2012 and 2013 (Figure $4 a, c)$. The $F_{7}$ RIL populations indicated that, although the $\mathrm{SH}$ parent had higher dormancy (15\%) than the BHA parent (8\%), the DGWG/SH RILs had high variability in dormancy within the population when evaluated at 150 DAH (Figure 5a). The mean dormancy of F7 DGWG/SH and BHA/DGWG mapping populations were 16.3 and $8.8 \%$, respectively. In contrast, when dormancy was measured $90 \mathrm{DAH}$ on $\mathrm{F}_{8}$ seeds, the BHA/DGWG RILs (5.5\%) had a greater dormancy than the SH population (3.5\%) (Figure 5c,d). The $\mathrm{F}_{8}$ DGWG/SH RILs 


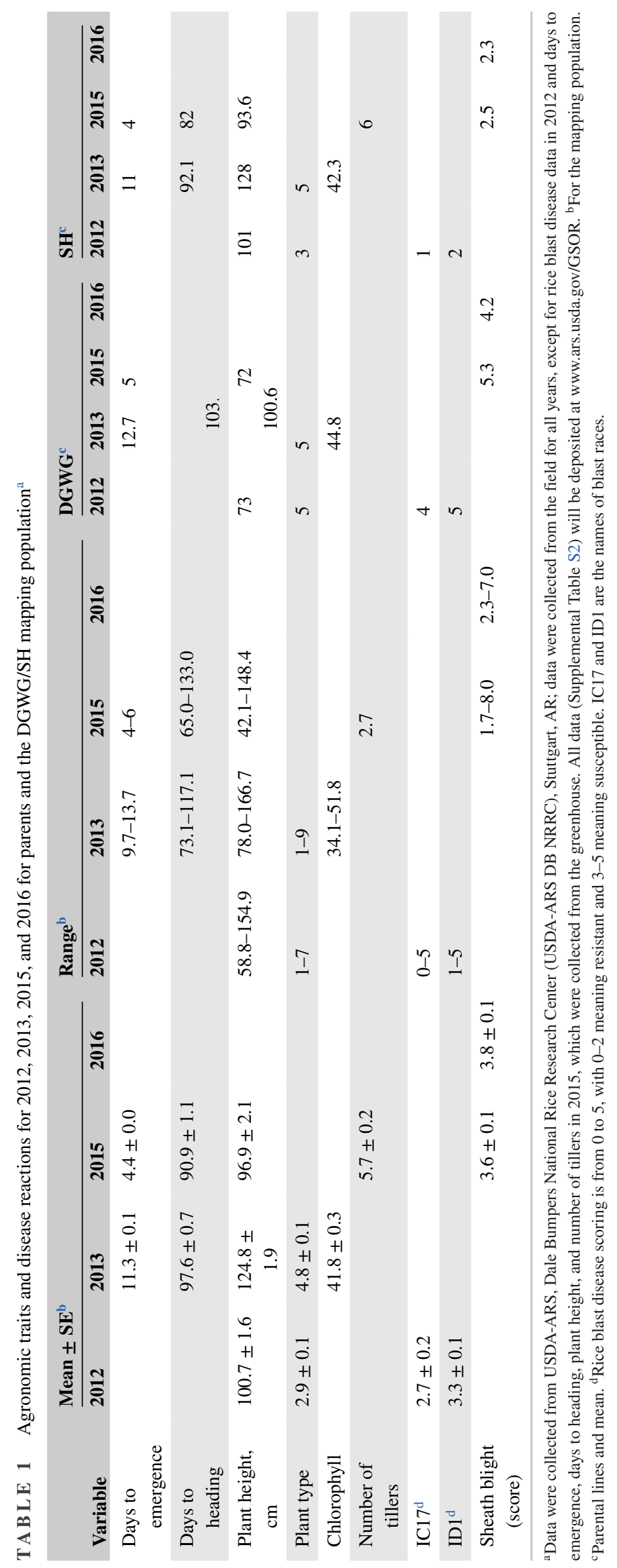




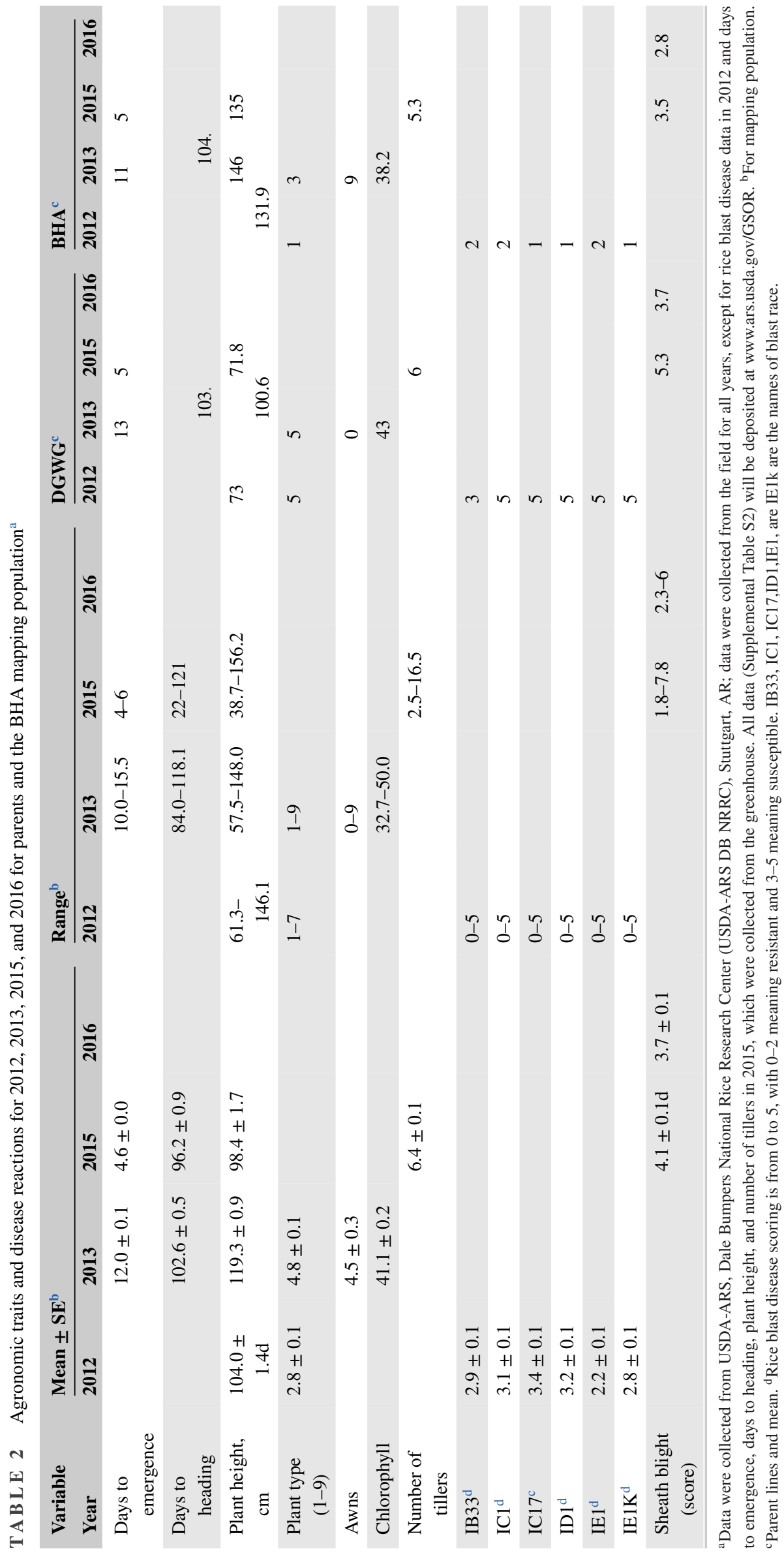




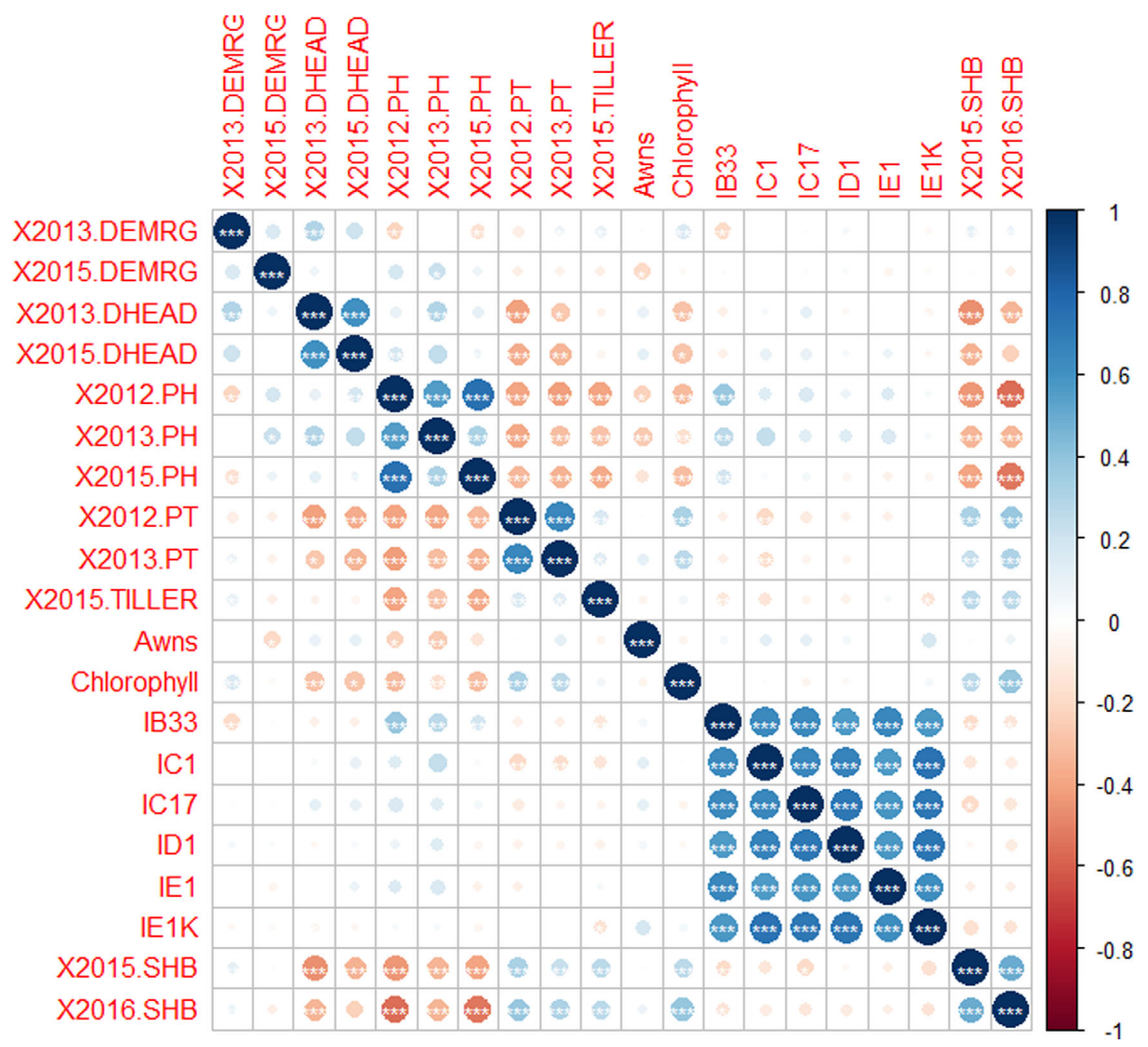

F I G U R E 2 Pearson's correlation matrix for all traits in the Table 2. The shaded scale refers to the strength of correlation. Significance levels (*95\%,**99\%,***99.9\%) are indicated. DEMRG, days to emergence; DHEAD, days to heading; IB33, IC1, IC17, ID1, IE1, IE1k, blast races; PH, plant height; PT, plant type; SHB, sheath blight reaction; TILLER, number of tillers. Years are indicated after X

were more similar to one another, and the majority of the them did not show greater dormancy than the parent population (Figure 5c). The dormancy percentage was greater and more variable in $\mathrm{F}_{7}$ RILs than in $\mathrm{F}_{8}$ RILs (Figure 5). However, no significant differences in dormancy were observed among inbred lines, except for $\mathrm{F}_{8}$ BHA/DGWG RILs (Figure $5 \mathrm{~d}$ ), when analyzed separately for each population in a year. A contrast analysis indicated consistent differences in dormancy between both weedy rice parents SH or BHA and DGWG.

\section{4 | DISCUSSION}

Combinations of numerous traits and characteristics such as dormancy have helped weedy rice persist as a dominant weed in rice fields. In general, straw hull and black hull ecotypes are phenotypically and genotypically different (Shivrain et al., 2010a, 2010b; Tseng et al., 2018). Previous studies have indicated that contemporary black hull ecotypes have higher intrapopulation variation in terms of dormancy than straw hull ecotypes (Do Lago, 1982; Tseng et al., 2013). It has been observed that black hull ecotypes require longer afterripening time to release dormancy (Tseng et al., 2013). However, the hybrids of weedy rice and rice cultivars are expected to show $>90 \%$ germination irrespective of hull color due to the introgression of crop alleles (Shivrain et al., 2009b; Singh et al., 2017).

In the current study, we found different seed dormancies of DGWG/SH and BHA/DGWG populations, and the dormancy differed between different time intervals of germination after harvest. However, lack of significant segregation at $\mathrm{F}_{7}$ and $\mathrm{F}_{8}$ might have led to the more uniform expression of dormancy among the RILs. Consistent with these results, $>96 \%$ of the genome in $\mathrm{F}_{7}$ or higher generation RILs often becomes homozygous and provides genetic stability (Al-kordy et al., 

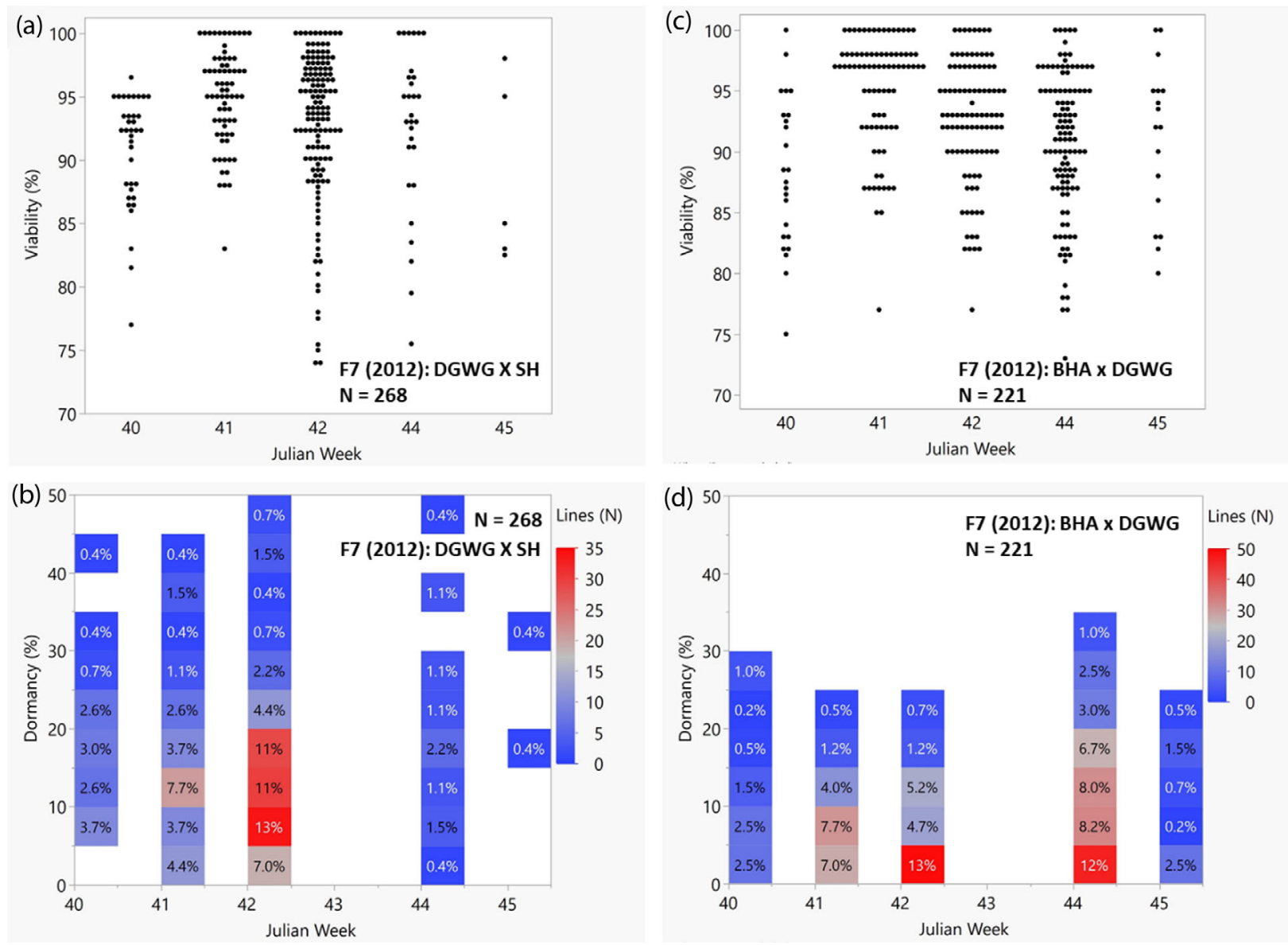

F I G U R E 3 Viability and dormancy of $\mathrm{F}_{7}$ DGWG/SH and BHA/DGWG mapping populations. Individual plants and seeds were harvested from October to November in 2012, and dormancy was measured at $150 \mathrm{~d}$ after harvest ( $20 \mathrm{wk}$ ) with respect to harvesting date (Julian week). (a) Viability and (b) dormancy of $\mathrm{F}_{7}$ DGWG/SH and (c) viability and (d) dormancy of $\mathrm{F}_{7}$ BHA/DGWG were plotted with respect to Julian week. For viability, each dot represents a seed from an individual plant of $\mathrm{F}_{7} \mathrm{DGWG} / \mathrm{SH}$ and $\mathrm{F}_{7} \mathrm{BHA} / \mathrm{DGWG}$. For dormancy, the color scheme and percentages in the boxes represent the number of recombinant inbred lines (RILs; percent of total) with a particular combination of Julian week and dormancy, where red highlights a greater number of RILs with corresponding dormancy level indicated by y-axis. All data will be deposited at www.ars.usda.gov/GSOR

2019; Zhang et al., 2006). This might have resulted in nonsignificant differences in dormancy among the RILs in the current study.

Transgressive segregation in these two mapping populations is useful to dissect genetic and epigenetic bases underlying weedy traits (Qi et al., 2015; Thurber et al., 2013). The weedy parents BHA and $\mathrm{SH}$ are taller than the indica parent DGWG and most cultivated rice in the southern United States, enabling lodging that reduces crop yield. Identified resistance genes to blast and sheath blight diseases are consistent with correlations of blast and sheath blight reactions we observed (Goad et al., 2020; Liu et al., 2015a). These newly identified resistance genes are new sources for breeders to use for marker-assisted breeding and for elucidating adaptive innate immunity in weedy rice. Among the most interesting of these traits are superior vigor and competitiveness throughout its life, population diversity and changeability facilitated by natural crossing with cultivars or other weedy rice genotypes, abundant production of seed, and high levels of seed shattering and dormancy, which assure deposition of large numbers of weedy rice seed into the soil, where they can infest the next crop or a future crop following multiple years of dormancy (Delouche et al., 2007). Some genes for seed shattering appear to be closely linked with a major gene for red bran color and quantitative trait loci for seed dormancy (Ji et al., 2006). From the mapping populations presented here, it is shown that weed-associated traits such as seed shattering are controlled by multiple quantitative trait loci, whereas awn length and seed bran color are mostly attributable to individual loci; the genetic "weedy" alleles derived from the two weedy rice genotypes have evolved in parallel through independent mechanisms (Qi et al., 2015). Much of the competitiveness of weedy rice is attributable to aggressive emergence and growth relating to profuse tillering; nitrogen fertilizer uptake; production of root, shoot, and seed biomass; and greater plant height (which causes lodging), all of which 

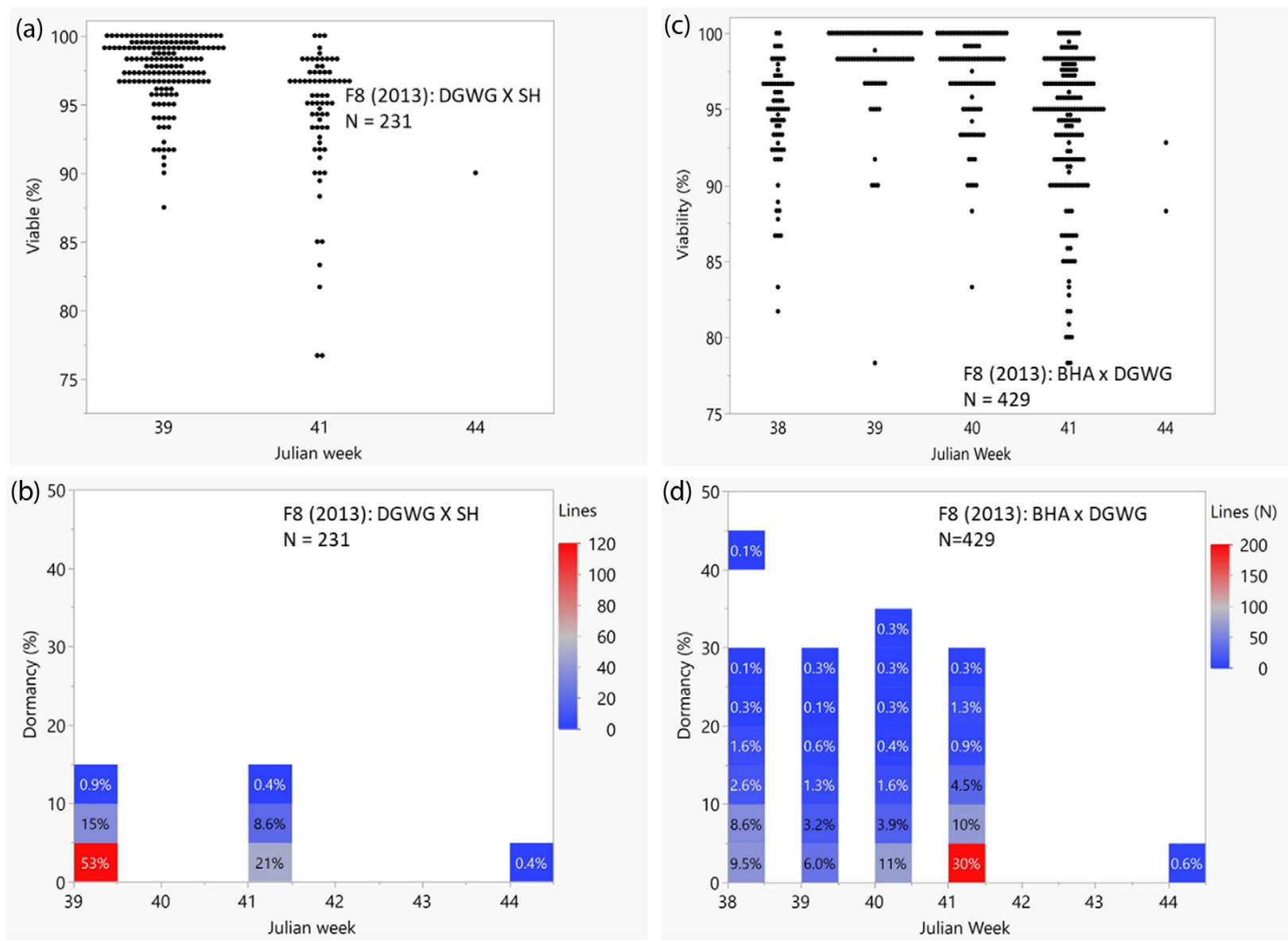

F I G U R E 4 Viability and dormancy of $\mathrm{F}_{8}$ DGWG/SH and BHA/DGWG mapping populations. Individual plants and seeds were harvested from October to November in 2013, and dormancy was measured at $90 \mathrm{~d}$ after harvest ( $12 \mathrm{wk}$ ) with respect to harvesting dates (Julian week). (a) Viability and (b) dormancy of $\mathrm{F}_{8}$ DGWG/SH and (c) viability and (d) dormancy of $\mathrm{F}_{8}$ BHA/DGWG were plotted with respect to Julian week of harvest. For viability, each dot represents a seed of an individual plant of $\mathrm{F}_{8}$ DGWG/SH and $\mathrm{F}_{8} \mathrm{BHA} / \mathrm{DGWG}$. For dormancy, the color scheme and percentages in the boxes represent the number of lines/ individuals (percent of total) with a particular combination of Julian week and dormancy, where red highlights a greater number of lines with corresponding dormancy level indicated by y-axis. All data (Supplemental Tables S3-S6) will be deposited at www.ars.usda.gov/GSOR

confer greater competitiveness in comparison with the crop, resulting in severe yield losses (Burgos et al., 2006; Jia \& Gealy, 2018; Sales et al., 2011; Shivrain et al., 2009a, 2009b, 2009c, 2010b). A single weedy rice plant has been shown to have the same yield-reducing potential as up to five cultivated rice plants (Pantone et al., 1992). Weedy rice also reduces grain quality because its red bran color is undesirable and its seeds are difficult and costly to separate from those of the white rice crop, which results in dockage and reduced commercial value (Delouche et al., 2007). Although the species is primarily self-pollinated, rice and weedy rice can intercross at low frequencies (usually $<0.5 \%$ ), sometimes producing new and difficult-to-control "weedy" progeny (Burgos et al., 2014; Gealy et al., 2015; Jia \& Gealy, 2018; Jia et al., 2014; Reagon et al., 2010; Shivrain et al., 2007, 2009a, 2009 b, 2009c). Weedy rice-cultivated rice outcrosses tend to become even more difficult to manage when rice cultivars carry genes for herbicide resistance, and such herbicide- resistant rice cultivars now make up more than half of the rice grown in the southern United States (Burgos et al., 2014; Norsworthy et al., 2013; Ziska et al., 2015). Deployment of herbicide-resistant rice cultivars in the southern United States over the past two decades has led to improved management and control of weedy rice but has also resulted in some challenges (Burgos et al., 2008; Norsworthy et al., 2013). New weedy rice genotypes have developed in some fields over time from intercrossing between weedy rice and herbicideresistant rice cultivars and intense selection from herbicides used with these cultivars, as well as from traditional avenues such as new introductions of weedy rice seed and intercrossing between different genotypes of weedy rice (Burgos et al., 2014; Gealy et al., 2012; Norsworthy et al., 2013). Newer rice cultivars tend to have earlier flowering times than older cultivars, and the earliest-flowering ones exhibit improved flowering synchronization and increased outcrossing with many of the naturally occurring, early-heading straw hull weedy 
(a)

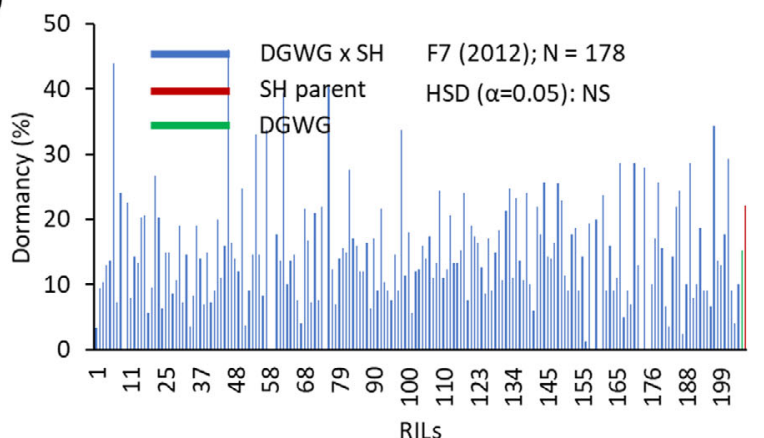

(c)

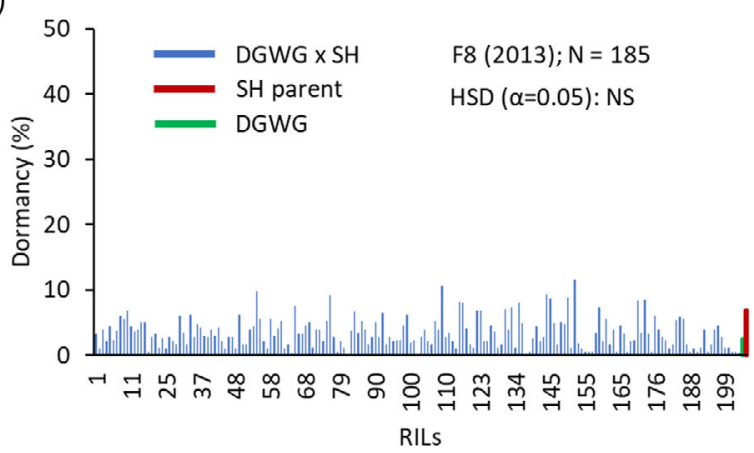

(b)

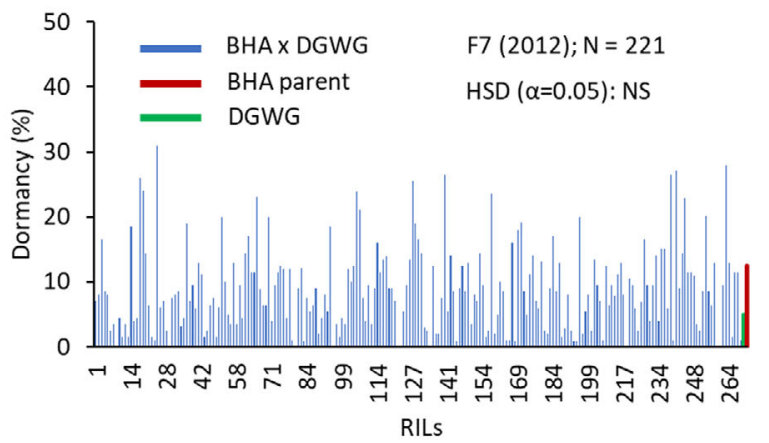

(d)

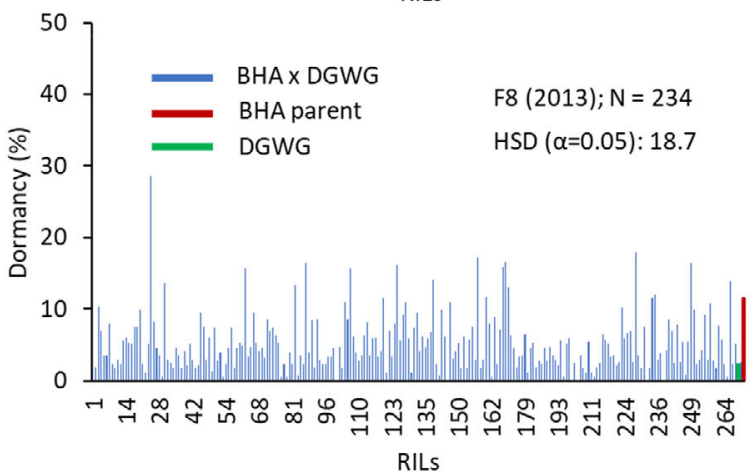

F I G U R E 5 Dormancy of $\mathrm{F}_{7}$ and $\mathrm{F}_{8}$ mapping populations (DGWG/SH and BHA/DGWG). Individual plants and seeds were harvested from October to November in 2012 and 2013, and dormancy was measured at 150 and $90 \mathrm{~d}$ after harvest for $\mathrm{F}_{7}$ and $\mathrm{F}_{8}$ recombinant inbred lines (RILs), respectively, based on their harvesting dates (Julian week). Dormancy of (a) $\mathrm{F}_{7}$ DGWG/SH, (b) $\mathrm{F}_{7}$ BHA/DGWG, (c) $\mathrm{F}_{8}$ DGWG /SH, and (d) $\mathrm{F}_{8}$ BHA/DGWG were plotted for each RIL along with its parents, irrespective of the week of harvest. Dormancy was averaged over three growth chamber replications for each of three field replications. The mean values of dormancy for $\mathrm{F}_{7} \mathrm{DGWG} / \mathrm{SH}=16 \%, \mathrm{~F}_{7} \mathrm{BHA} / \mathrm{DGWG}=8.8 \%, \mathrm{~F}_{8}$ DGWG/SH $=3.5 \%$, and $\mathrm{F}_{8} \mathrm{BHA} / \mathrm{DGWG}=5.5 \%$. All data (Supplemental Tables S3-S7) will be deposited at www.ars.usda.gov/GSOR

rice genotypes. However, a biological bottleneck between outcrossing and permanent gene flow into weedy rice populations apparently has mitigated the impact of this increased outcrossing activity somewhat because $F_{1}$ hybrids from crosses with straw hull weedy rice genotypes usually flower extremely late, which largely prevents production of viable $F_{2}$ seed (Jia \& Gealy, 2018; Shivrain et al., 2009a). There is evidence to suggest that gene flow from rice into modern populations of black hull weedy rice has been greater than into those of straw hull weedy rice (Burgos et al., 2014).

\section{5 | CONCLUSIONS}

Future challenges from weedy rice may arise due to shifts in cultural practices or soil microbes or environmental conditions. Negative impacts of weedy rice worldwide have increased in recent years, particularly where direct-seeding or drill-seeding practices have replaced traditional water-seeded or transplanting systems that previously had held weedy rice in check due to the weed control benefits of maintaining permanent flood at planting and throughout the growing season
(Ziska et al., 2012). Weedy rice is likely to become an even greater weed problem under projected future climate conditions because recent research showed that the relative growth aggressiveness of weedy rice and outcrossing between weedy rice and cultivated rice increased under simulated environmental changes, such as increases in ambient $\mathrm{CO}_{2}$ levels and temperature (Wang et al., 2016; Ziska et al., 2012). Alternative rice irrigation systems such as alternate wetting and drying, which conserves irrigation water and is being developed and deployed in the United States and worldwide, may also result in new and unpredictable interactions between weedy rice and cultivated rice in the fields. Because weed-crop RILs may also cause problems in fields due to the weedy traits, it is preferable to work under highly contained environmental conditions, such as in the greenhouse. Nevertheless, these genetic resources characterized for agronomic traits. including dormancy and disease reactions, along with abundant genetic markers of all RILs and parents are thus important for investigating the genetic interactions of weedy rice and cultivated rice under different cultural practices and changing environments. The resulting knowledge will benefit functional genomics, breeding, and crop protection. 


\section{6 | AVAILABILITY}

These two mapping populations with the accompanying genetic and phenotypic information provide a valuable foundation for association mapping, understanding the basis of beneficial traits for crop improvement, and insights into the molecular dynamics of the evolution of invasive weed species of rice and their management. The $\mathrm{F}_{8}$ generation seeds from 2013 are available for distribution. Seeds of two weedy rice mapping populations, the DGWG (GSOR 301040) and straw hull type AR-2000-1135-01 (PI 653435), referred as SH, and the late-flowering black hull type MS-1996-9 (PI 653419), referred as BHA, will be maintained by Dr. Yulin Jia of the USDA-ARS Dale Bumpers National Rice Research Center, Stuttgart, AR. Distribution of seeds will be made by the USDA-ARS Genetic Stock Collection of Oryza sativa (http:// www.ars.usda.gov/main/docs.htm?docid=8318), where they are available for research purposes, including development and commercialization of new materials. It is requested that appropriate recognition of the source be given when these lines contribute to the research or development of improved lines, cultivars, or hybrids.

\section{DATA AVAILABILITY STATEMENT}

All phenotypic data and genotypes of these two populations and parents generated by genotyping by sequencing can be accessed at www.ars.usda.gov/GSOR and the DRYAD Digital Repository at https://datadryad.org/stash/dataset/ https:// doi.org/10.5061/dryad.566h9, and Illumina HiSeq Raw reads: NCBI SRA accession SRX576894, respectively.

\section{ACKNOWLEDG MENTS}

The authors thank Tracy Bianco, Howard Black, Laduska Sells, Michael Lin, Kristina Trahern, and Heather Box at Dale Bumpers National Rice Research Center (DB NRRC) for their excellent technical assistance. We thank Ms. Deborah L Boykin (Southeast area, statistician, Stoneville, MS) and Dr. Xueyan Wang (Noble Research Institute, Ardmore, OK) for help on all statistical analyses. This work was supported in part by the National Science Foundation Plant Genome Research Program (NSF awards IOS-1032023 and PGR1947609). For critical reviews, we thank Anna McClung, Melissa H. Jia, Jai Rohila, and Trevis Huggins (USDA-ARS DB NRRC). USDA is an equal opportunity provider and employer.

\section{AUTHOR CONTRIBUTIONS}

Yulin Jia: Conceptualization; Data curation; Formal analysis; Funding acquisition; Investigation; Methodology; Project administration; Resources; Software; Supervision; Validation; Visualization; Writing-original draft; Writing-review \& editing. Vijay Singh: Data curation; Formal analysis;
Writing-review \& editing. David Gealy: Conceptualization; Data curation; Writing-review \& editing. Yan Liu: Data curation; Writing-review \& editing. Jianbing Ma: Data curation; Writing-review \& editing. Carrie Thurber: Data curation; Writing-review \& editing. Nilda Roma-Burgos: Conceptualization; Writing-review \& editing. Kenneth M. Olsen: Conceptualization; Resources; Writing-review \& editing. Ana Caicedo: Conceptualization; Resources; Writingreview \& editing.

\section{CONFLICTOF INTEREST}

The authors declare no conflict of interest.

\section{O R C I D}

Yulin Jia (1) https://orcid.org/0000-0002-2132-0498 Nilda Roma-Burgos (1) https://orcid.org/0000-0002-69776873

Kenneth M. Olsen (1) https://orcid.org/0000-0002-8338-3638

\section{RE F E R E N C E S}

Al-Kordy, M. A., Ibrahim, H. F., El-Mouhamady, A. B. A., \& AbdelRahman, H. M. (2019). Genetic stability analysis and molecular depiction in elite entries of rice (Oryza sativa L.). Bulletin of the National Research Centre, 43, 85. https://doi.org/10.1186/s42269019-0100-3

Burgos, N. R., Norman, R. J., Gealy, D. R., \& Black, H. L. (2006). Competitive $\mathrm{N}$ uptake between rice and weedy rice. Field Crops Research, 98, 1-7.

Burgos, N. R., Norsworthy, J. K., Scott, R. C., \& Smith, K. L. (2008). Red rice (Oryza sativa) status after 5 years of imidazolinone-resistant rice technology in Arkansas. Weed Technology, 22, 200-208. https: //doi.org/10.1614/WT-07-075.1

Burgos, N. R., Singh, V., Tseng, T. M., Black, H., Young, N. D., Huang, Z., Hyma, K. E., Gealy, D. R., \& Caicedo, A. L. (2014). The impact of herbicide-resistant rice (Oryza sativa L.) technology on phenotypic diversity and population structure of U.S. weedy rice. Plant Physiology, 166, 1208-1220. https://doi.org/10.1104/pp.114.242719

De Leon, T. B., Karn, E., Al-Khatib, K., Espino, L., Blank, T., Andaya, C. B., Andaya, V. C., \& Brim-Deforest, W. (2019). Genetic variation and possible origins of weedy rice found in California. Ecology Evolution, 9, 5835-5848. https://doi.org/10.1002/ece3.5167

Delouche, J. C., Burgos, N. R., Gealy, D. R., de San Martin, Z., Labrada, R., Larinde, M., \& Rosell, C. (2007). Weedy rices: Origin, biology, ecology and control (Plant Production and Protection Paper 188). FAO.

Do Lago, A. A. (1982). Characterization of red rice (Oryza sativa L.) phenotypes in Mississippi [Doctoral dissertation]. Mississippi State University.

Gealy, D. H., Agrama, H., \& Jia, M. H. (2012). Genetic analysis of atypical U.S. red rice phenotypes: Indications of prior gene flow in rice fields? Weed Science, 60, 451-461. https://doi.org/10.1614/WS-D11-00159.1

Gealy, D. R., Burgos, N. R., Yeater, K. M., \& Jackson, A. K. (2015). Outcrossing potential between U.S. blackhull red rice and indica rice cultivars. Weed Science, 63, 647-657. https://doi.org/10.1614/WS-D14-00150.1 
Gealy, D. R., Rohila, J. S., \& Boykin, D. L. (2019). Genetic potential of rice under alternate-wetting-and-drying irrigation management for barnyardgrass (Echinochloa crus-galli) suppression and grain yield production. Weed Science, 67, 453-462. https://doi.org/10.1017/wsc. 2019.24

Goad, D. M., Jia, Y., Gibbons, A., Liu, Y., Gealy, D., Caicedo, A. L., \& Olsen, K. M. (2020). Identification of novel QTLs conferring sheath blight resistance in two weedy rice mapping populations. Rice, 13, 21. https://doi.org/10.1186/s12284-020-00381-9

Gonzalez, R. (2019). Contrasts and post hoc tests, version 2.8. http:// www-personal.umich.edu/ gonzo/coursenotes/file3.pdf

Ji, H.-S., Chu, S.-H., Jiang, W., Cho, Y.-I., Hahn, J.-H., Eun, M.-Y., Mccouch, S. R., \& Koh, H.-J. (2006). Characterization and mapping of a shattering mutant in rice that corresponds to a block of domestication genes. Genetics, 173, 995-1005. https://doi.org/10. 1534/genetics.105.054031

Jia, S., Yuan, Q., Pei, X., Wang, F., Hu, N., Yao, K., \& Wang, Z. (2014). Rice transgene flow: Its patterns, model and risk management. Plant Biotechnology Journal, 12, 1259-1270. https://doi.org/10.1111/pbi. 12306

Jia, Y., \& Gealy, D. (2018). Weedy red rice has novel resistance resources to biotic stress. The Crop Journal, 6, 443-450. https://doi.org/10. 1016/j.cj.2018.07.001

Kanapeckas, K. L., Vigueira, C. C., Ortiz, A., Gettler, K. A., Burgos, N. R., Fischer, A. J., \& Lawton-Rauh, A. L. (2016). Escape to ferality: The endoferal origin of weedy rice from crop rice through dedomestication. PLOS ONE, 11, e0162676. https://doi.org/10.1371/journal. pone.0162676

Karn, E., De Leon, T., Espino, L., Al-Khatib, K., \& Brim-Deforest, W. (2020). Phenotypic diversity of weedy rice (Oryza sativa f. spontanea) biotypes found in California and implications for management. Weed Science, 68, 485-495. https://doi.org/10.1017/wsc.2020.43

Li, L., \& Olsen, K. M. (2020). Population genomics of weedy crop relatives: Insights from weedy rice. In O. P. Rajora (Ed.), Population genomics: Crop plants. Springer Nature. https://doi.org/10.1007/ $13836 \_2020 \quad 77$

Li, L.-F., Li, Y.-L., Jia, Y., Caicedo, A. L., \& Olsen, K. M. (2017). Signatures of adaptation in the weedy rice genome. Nature Genetics, 49 , 811-814. https://doi.org/10.1038/ng.3825

Liu, G., Jia, Y., Mcclung, A., Oard, J. H., Lee, F. N., \& Correll, J. C. (2013). Confirming QTLs and finding additional loci responsible for resistance to rice sheath blight disease. Plant Disease, 97, 113-117. https://doi.org/10.1094/PDIS-05-12-0466-RE

Liu, Y., Qi, X., Gealy, D. R., Olsen, K. M., Caicedo, A. L., \& Jia, Y. (2015a). QTLs analysis for resistance to blast disease in US weedy rice. Molecular Plant-Microbe Interactions, 7, 834-844. https://doi. org/10.1094/MPMI-12-14-0386-R

Liu, Y., Qi, X., Young, N. D., Olsen, K. M., Caicedo, A. L., \& Jia, Y. (2015b). Characterization of resistance genes to rice blast fungus Magnaporthe oryzae in a "Green Revolution" rice variety. Molecular Breeding, 35, 52. https://doi.org/10.1007/s11032-015-0256-y

Londo, J. P., \& Schaal, B. A. (2007). Origins and population genetics of weedy red rice in the USA. Molecular Ecology, 16, 4523-4535. https://doi.org/10.1111/j.1365-294X.2007.03489.x

Norsworthy, J. K., Burgos, N. R., Scott, R. C., \& Smith, K. L. (2007). Consultant perspectives on weed management needs in Arkansas rice. Weed Technology, 81, 832-839. https://doi.org/10.1614/WT-06-203. 1
Norsworthy, J. K., Bond, J., \& Scott, R. C. (2013). Weed management practices and needs in Arkansas and Mississippi rice. Weed Technology, 27, 623-630. https://doi.org/10.1614/WT-D-12-00172.1

Ottis, B. V., Smith, K. L., Scott, R. C., \& Talbert, R. E. (2005). Rice yield and quality as affected by cultivar and red rice (Oryza sativa) density. Weed Science, 53, 499-504. https://doi.org/10.1614/WS-04-154R

Pantone, D. J., Baker, J. B., \& Jordan, P. W. (1992). Path analysis of red rice (Oryza sativa L.) competition with cultivated rice. Weed Science, 40, 313-319. https://doi.org/10.1017/S0043174500057404

Qi, X., Liu, Y., Vigueira, C. C., Young, N. D., Caicedo, A. L., Jia, Y., Gealy, D. R., \& Olsen, K. M. (2015). More than one way to evolve a weed: Parallel evolution of U.S. weedy rice through independent genetic mechanisms. Molecular Ecology, 24, 3329-3344. https://doi. org/10.1111/mec.13256

Qiu, J., Jia, L., Wu, D., Weng, X., Chen, L., Sun, J., Chen, M., Mao, L., Jiang, B., Ye, C., Turra, G., Guo, L., Ye, G., Zhu, Q.-H., Imaizumi, T., Song, B.-K., Scarabel, L. Merotto, A. Jr, Olsen, K. M., \& Fan, L. (2020). Diverse genetic mechanisms underlie worldwide convergent rice feralization. Genome Biology, 21, 70. https://doi.org/10.1186/ s13059-020-01980- x

Reagon, M., Thurber, C. S., Gross, B. L., Olsen, K. M., Jia, Y., \& Caicedo, A. L. (2010). Genomic patterns of nucleotide diversity in divergent populations of U.S. weedy rice. BMC Evolutionary Biology, 10, 180. https://doi.org/10.1186/1471-2148-10-180

Roychowdhury, M., Jia, Y., Jackson, A., Jia, M. H., Fjellstrom, R., \& Cartwright, R. D. (2012). Analysis of rice blast resistance gene $\mathrm{Pi}-\mathrm{Z}$ using pathogenicity assays and DNA markers. Euphytica, 184, 35-47. https://doi.org/10.1007/s10681-011-0481-3

Sales, M. A., Burgos, N. R., Shivrain, V. K., Murphy, B., \& Gbur, E. E., Jr. (2011). Morphological and physiological responses of weedy red rice (Oryza sativa L.) and cultivated rice (O. sativa) to N supply. American Journal of Plant Sciences, 2, 569-577. https://doi.org/10. 4236/ajps.2011.24068

Shivrain, V. K., Burgos, N. R., Agrama, H. A., Lawton-Rauh, A., Lu, B., Sales, M. A., Boyett, V. A., Gealy, D. R., \& Moldenhauer, K. K. (2010a). Genetic diversity of weedy red rice (Oryza sativa L.) in Arkansas, USA. Weed Research, 50, 289-302.

Shivrain, V. K., Burgos, N. R., Anders, M. M., Rajguru, S. N., Moore, J., $\&$ Sales, M. A. (2007). Gene flow between Clearfield ${ }^{\mathrm{TM}}$ rice and red rice. Crop Protection, 26, 349-356. https://doi.org/10.1016/j.cropro. 2005.09.019

Shivrain, V. K., Burgos, N. R., Gealy, D. R., Sales, M. A., \& Smith, K. L. (2009a). Gene flow from weedy red rice (Oryza sativa L.) to cultivated rice and fitness of hybrids. Pest Management Science, 65, 1124-1129. https://doi.org/10.1002/ps. 1802

Shivrain, V. K., Burgos, N. R., Gealy, D. R., Smith, K. L., Scott, R. C., Mauromoustakos, A., \& Black, H. (2009b). Red rice (Oryza sativa L.) emergence characteristics and influence on rice (O. sativa) yield at different planting dates. Weed Science, 571, 94-102. https://doi.org/ 10.1614/WS-08-112.1

Shivrain, V. K., Burgos, N. R., Sales, M. A., Mauromoustakos, A., Gealy, D. R., Smith, K. L., Black, H. L., \& Jia, M. (2009c). Factors affecting the outcrossing rate between Clearfield ${ }^{\mathrm{TM}}$ rice and red rice (Oryza sativa). Weed Science, 57, 394-403. https://doi.org/10.1614/WS-09003.1

Shivrain, V. K., Burgos, N. R., Scott, R. C., Gbur, E. E., Estorninos, L. E., $\&$ McClelland, M. R. (2010b). Phenotypic diversity of weedy red rice (Oryza sativa L.) in Arkansas, USA in relation to weed management. 
Crop Protection, 29, 721-730. https://doi.org/10.1016/j.cropro.2010. 02.010

Singh, V., Singh, S., Black, H., Boyett, V., Basu, S., Gealy, D., Gbur, E., Pereira, A., Scott, R. C., Caicedo, A., \& Burgos, N. R. (2017). Introgression of Clearfield ${ }^{\mathrm{TM}}$ rice crop traits into weedy red rice outcrosses. Field Crops Research, 207, 13-23. https://doi.org/10.1016/j. fcr.2017.03.004

Smith, R. J. (1988). Weed thresholds in Southern U.S. rice, Oryza sativa. Weed Technology, 2, 232-241. https://doi.org/10.1017/ S0890037X00030505

Thurber, C. S., Jia, M. H., Jia, Y., \& Caicedo, A. L. (2013). Similar traits, different genes? Examining convergent evolution in related weedy rice populations. Molecular Ecology, 22, 685-698. https://doi.org/10. 1111/mec. 12147

Tseng, T. M., Burgos, N. R., Shivrain, V. K., Alcober, E. A., \& Mauromoustakos, A. (2013). Inter- and intrapopulation variation in dormancy of Oryza sativa (weedy red rice) and allelic variation in dormancy-linked loci. Weed Research, 53, 440-451. https://doi.org/ 10.1111/wre. 12044

Tseng, T.-M., Shivrain, V. K., Lawton-Rauh, A., \& Burgos, N. R. (2018). Dormancy-linked population structure of weedy rice (Oryza sp.). Weed Science, 66, 331-339. https://doi.org/10.1017/wsc.2017.86

Wamishe, Y. A., Yulin, J., Singh, P., \& Cartwright, R. D. (2007). Identification of field isolates of Rhizoctonia solani to detect quantitative resistance in rice under greenhouse conditions. Frontiers of Agriculture in China, 1,361-367. https://doi.org/10.1007/s11703-007-00614

Wang, D. R., Bunce, J. A., Tomecek, M. B., Gealy, D., McClung, A., McCouch, S. R., \& Ziska, L. H. (2016). Evidence for divergence of response in Indica, Japonica, and wild rice to high $\mathrm{CO}_{2} \times$ temperature interaction. Global Change Biology, 22, 2620-2632. https://doi.org/ 10.1111/gcb.13279

Wedger, M. J., Topp, C. N., \& Olsen, K. M. (2019). Convergent evolution of root system architecture in two independently evolved lineages of weedy rice. New Phytologist, 223, 1031-1042. https://doi.org/10. 1111/nph. 15791
Zhang, Y., Luo, L., Xu, C., Zhang, Q., \& Xing, Y. (2006). Quantitative trait loci for panicle size, heading date and plant height co-segregating in trait-performance derived near-isogenic lines of rice (Oryza sativa). Theoretical and Applied Genetics, 113, 361-368. https://doi.org/10. 1007/s00122-006-0305-3

Zhu, J., Tremblay, N., \& Liang, Y. (2012). Comparing SPAD and atLEAF values for chlorophyll assessment in crop species. Canadian Journal of Soil Science, 92, 645-648. https://doi.org/10.4141/cjss2011-100

Ziska, L. H., Gealy, D. R., Tomecek, M. B., Jackson, A. K., \& Black, H. L. (2012). Recent and projected increases in atmospheric $\mathrm{CO}_{2}$ concentration can enhance gene flow between wild and genetically altered rice (Oryza sativa). PLOS ONE, 7(5), e37522. https://doi.org/ 10.1371/journal.pone.0037522

Ziska, L. H., Gealy, D. R., Burgos, N., Caicedo, A. L., Gressel, J., Lawton-Rauh, A. L., Avila, L. A., Theisen, G., Norsworthy, J., Ferrero, A., Vidotto, F., Johnson, D. E., Ferreira, F. G., Marchesan, E., Menezes, V., Cohn, M. A., Linscombe, S., Carmona, L., Tang, R., $\&$ Merotto, A. (2015). Weedy (red) rice: An emerging constraint to global rice. Advances in Agronomy, 129, 181-228. https://doi.org/10. 1016/bs.agron.2014.09.003

\section{SUPPORTING INFORMATION}

Additional supporting information may be found in the online version of the article at the publisher's website.

How to cite this article: Jia, Y., Singh, V., Gealy, D., Liu, Y., Ma, J., Thurber, C., Roma-Burgos, N., Olsen, K. M., \& Caicedo, A. Registration of two rice mapping populations using weedy rice ecotypes as a novel germplasm resource. $J$ Plant Regist. 2022;16:162-175. https://doi.org/10.1002/plr2.20174 